\title{
OS FIOS VISÍVEL E INVISÍVEL DA EXPERIÊNCIA DO EXAME FÍSICO PARA O CLIENTE ${ }^{1}$
}

\author{
Graciela da Silva Miguéis Salomão², Rosemeiry Capriata de Souza Azevedo
}

\footnotetext{
${ }^{1}$ Resultado parcial da dissertação - A experiência do exame físico para o cliente: um olhar fenomenológico. Programa de PósGraduação em Enfermagem da Faculdade de Enfermagem da Universidade Federal de Mato Grosso (UFMT), 2010.

${ }^{2}$ Mestranda do Programa de Pós-Graduação em Enfermagem da Faculdade de Enfermagem da UFMT. Mato Grosso, Brasil. E-mail: gracielasalomao@yahoo.com.br

${ }^{3}$ Doutora em Enfermagem. Docente do Programa de Pós-Graduação em Enfermagem da UFMT, Mato Grosso. Brasil. E-mail: capriata@terra.com.br
}

RESUMO: Estudo qualitativo de abordagem fenomenológica, que teve por objetivo desvelar a experiência do exame físico para o cliente. Os dados foram coletados nos meses de abril a julho/2009, por meio de entrevista semiestruturada com 14 clientes que passaram pela experiência do exame físico em um hospital universitário de Cuiabá-MT, a partir da questão norteadora: "Conte-me como foi a sua experiência em relação ao exame físico". Os dados foram organizados pela técnica de Giorgi e analisados com base na fenomenologia da percepção de Merleau-Ponty. A unidade de significado emergida foi: O exame físico localiza a doença no corpo, tornando visível o invisível. O fenômeno se desvelou como procedimento importante, capaz de localizar a doença no corpo, utilizando para isso técnicas específicas tais como a inspeção, palpação, percussão e ausculta. Conclui-se que há necessidade de rever as práticas profissionais e dar voz aos clientes que vivenciam a experiência em seu corpo.

DESCRITORES: Enfermagem. Exame físico. Corpo humano.

\section{THE VISIBLE AND INVISIBLE WARES OF THE PHYSICAL EXAMINATION FOR THE CUSTUMER}

\begin{abstract}
The qualitative study of phenomenology boarding, that had the purpose to reveal the physical examination experience for the custumer. The data were colected in the months of april and July of two thousand and nine, trough the semi-structures interview with fourteen custumers that had the physical examination experience in a University Hospital in Cuiabá-MT from the question about the topic "Tell me about your physical examination relation". The information were organized by Giorgi and analyzed based on the Merleau-Ponty comprehension. The unit of meaning emerged was: The physical examination finds the disease in the body making visible the inviseble. The phenomenon revealed the important process, able to locate the disease of the body, and because of this use specific techniques just like inspection, palpation, percussoes and auscultation. Concluded the need to review the profitional practies to give voice to the costomers who lived the experience in your body.
\end{abstract}

DESCRIPTORS: Nursing. Physical examination. Human body.

\section{LOS HILOS VISIBLES E INVISIBLES DE LA EXPERIÊNCIA DEL EXAMEN FÍSICO PARA EL CLIENTE}

\begin{abstract}
RESUMEN: Estúdio cualitativo de enfoque fenomenológico, que tuvo por objeto revelar la experiencia del examen físico para el cliente. La recopilación de datos fueron los meses de abril hasta julio del 2009, por médio de une encuesta semiestructurada com 14 clientes que pasaron por la experiencia del examen físico em un hospital universitario de Cuiaba em Mato Grosso, a partir de la cuestión norteadora "Cuêntame como fue su experiencia en relación al examen físico". Los datos fueron organizados por la técnica de Giorgi y analisados con base em la fenomenologia de la percepción de Merleau-Ponty. La unidad de significado emergida fue: El examen localiza la enfermedad en el cuerpo, convertiéndose en visible o invisible. El fenomeno se mostrá como procedimiento importante, capaz de localizar la enfermedad en el cuerpo, y para eso, utiliza técnicas especificas tales como la inspección, palpación, percusión y ausculta. Concluye que hay la necesidad de rever las praticas profesionales y dar voz a los clientes que vivenciam la experiência en su cuerpo.

DESCRIPTORES: Enfermería. Examen físico. Cuerpo humano.
\end{abstract}




\section{INTRODUÇÃO}

O presente estudo é resultado parcial da dissertação de Mestrado em Enfermagem desenvolvida no Programa de Pós-Graduação da Faculdade de Enfermagem da Universidade Federal de Mato Grosso, em Cuiabá-MT, e o objeto de investigação vinculado ao Grupo de Pesquisa Argos, linha de pesquisa: trabalho, cuidados e subjetividades em saúde e enfermagem.

O exame físico é um procedimento que faz parte do cotidiano profissional do enfermeiro (a) na prestação do cuidado de enfermagem. Este procedimento se realiza pelas técnicas de inspecção, palpação, percussão e ausculta, o que permite a aproximação do profissional de saúde/enfermagem com o corpo do cliente, e tem sua importância na medida em que aponta as alterações biofisiológicas que estão ocorrendo no corpo do cliente causandolhe doença. ${ }^{1}$ Serve ainda para orientar a equipe de saúde/enfermagem no tratamento das doenças.

A visão de corpo na saúde está intimamente ligada ao processo de institucionalização do hospital e nascimento do modelo clínico de atendimento à saúde, ou seja, cuidado voltado para as alterações anátomo-fisiológicas do corpo. O hospital, por sua vez, deixa de ser abrigo de pobres e doentes e se transforma em local de formação e aprimoramento científico. Neste espaço, o "poder médico" reside na capacidade de intervenção sobre a doença e a morte, ao adotar o modelo clínico de diagnóstico e tratamento. ${ }^{2}$

O que se observa na prática profissional e até mesmo no ensino é que o exame físico tem se focado quase que exclusivamente no desenvolvimento de habilidades técnicas e procedimentais em busca de alterações biológicas no corpo. Entretanto, o cliente deve ser visto para além do objeto de cuidado da equipe de saúde/enfermagem, ou seja, como sujeito que está presente no mundo e se relaciona com este por meio de seu corpo, das suas experiências, as quais lhe possibilitam ter seus próprios sentimentos, reações, interpretações, percepções a respeito do cuidado que lhe é dispensado.

Nesse sentido corroboramos com o filósofo Merleau-Ponty ao afirmar que "[...] corpo que percebe e é simultaneamente percebido; que deve deixar de ser compreendido apenas como objeto; [...] é a partir do corpo próprio, do corpo vivido, que posso estar no mundo em relação com os outros e com as coisas" . 3:161

A percepção é construída com base no diálogo com a psicologia, por isso está fundada na experiência do sujeito encarnado, do sujeito que olha, sente e, nessa experiência vivida por meio do corpo, fenomenal (corpo com experiências anteriores e dá um sentido a elas) é que se reconhece o espaço como expressivo e simbólico. ${ }^{3}$ Assim, não se pode pensar o sujeito como uma parte do mundo, simples objeto da biologia, pois tudo que se sabe do mundo, mesmo pela ciência, é a partir da própria visão/ experiência do mundo da vida.

A percepção está relacionada à atitude corpórea, à consciência do sujeito pensante e esta o convida a avaliar as coisas a partir dos diferentes olhares de mundo. "A percepção não é uma ciência do mundo, não é nem mesmo um ato, uma tomada de posição deliberada; ela é o fundo sobre o qual todos os atos se destacam e ela é pressuposta por eles" 3:6

Por meio da percepção podemos apreender e interpretar as coisas, o mundo ao nosso redor, abrindo uma possibilidade de entrarmos no mundo da experiência vivida pelo outro. A percepção se dá sempre em uma relação com o corpo.

Pensando assim, é que surgiram os questionamentos: Como é a experiência do exame físico para o cliente? Qual o significado do exame físico para o cliente?

Ao consultar a literatura nacional produzida na última década, na busca de trabalhos relacionados à temática foi possível identificar que as discussões pertinentes ao exame físico perpassam pela relevância que o mesmo tem seja na academia ou no serviço. ${ }^{4-8}$ Outras investigações têm como foco a percepção de crianças hospitalizadas sobre a realização de exames laboratoriais/imagens, ou a percepção da mulher e seu perfil epidemiológico sobre o exame colpocitológico. ${ }^{9-13}$ Identificamos, portanto, que existe uma lacuna no conhecimento produzido, até então, sobre a experiência do cliente em relação ao exame físico, o que nos motivou a descrever a visão do outro, de quem está no leito, não para buscar relações causais, mas para tentar compreender como se dá a experiência do exame físico para o cliente.

Desvelar a experiência do exame físico para o cliente poderá fornecer subsídios para que os profissionais de saúde desenvolvam práticas de cuidado que favoreçam a aproximação e o entendimento entre quem cuida e quem é cuidado. Assim, o estudo teve por objetivo desvelar a experiência do exame físico para o cliente.

\section{METODOLOGIA}

Estudo qualitativo de abordagem fenomenológica. A fenomenologia foi desenvolvida inicial- 
mente pelo filósofo alemão Edmund Husserl, no alvorecer do século XX, na Alemanha. Para este filósofo a fenomenologia é definida como uma "volta às coisas mesmas", ou seja, um retorno aos fenômenos, sendo este aquilo que aparece à consciência, que ocorre como objeto intencional. ${ }^{14}$ Dessa maneira, tal opção se deve ao fato de ser a corrente teórica que busca desvelar a essência da experiência, a partir de situações vivenciadas pelos sujeitos no contexto em que estas ocorrem. ${ }^{15} \mathrm{O}$ desvelar da experiência do exame físico para o cliente foi compreendido a partir da fenomenologia da percepção desenvolvida por Merleau-Ponty.

Os participantes deste estudo foram quatorze clientes internados nas clínicas médica e cirúrgica de um hospital universitário em Cuiabá-MT e que passaram pela experiência do exame físico. Os requisitos para a participação dos sujeitos no estudo foram: idade superior a 18 anos, para ambos os sexos, ter sido internado nas clínicas médica e cirúrgica por um período mínimo de 48 horas, em condição de verbalização, ser residente no município de Cuiabá-MT e ter recebido alta hospitalar no período de um mês. O número de participantes foi definido por meio da saturação de dados, ou seja, até o momento em que nenhuma informação nova foi acrescentada. ${ }^{15}$

A coleta de dados ocorreu no período de abril a julho de 2009. A entrevista semi-estruturada foi o recurso metodológico utilizado para a coleta dos dados a partir da seguinte questão norteadora: "Conte-me como foi a sua experiência em relação ao exame físico". Os locais escolhidos pelos clientes para a realização das entrevistas foram o ambulatório do hospital universitário ou a sua residência. Independentemente do local das entrevistas, estas foram realizadas após a assinatura do Termo de Consentimento Livre e Esclarecido.

As entrevistas foram gravadas, em seguida transcritas na íntegra e para garantir o anonimato dos entrevistados estes foram identificados com numeração sequencial E1, E2.... E14.

A análise fenomenológica seguiu as etapas propostas por Amadeo Giorgi: leitura do conjunto do material (entrevistas) para se ter uma ideia do todo; em seguida, especificar as unidades de significado a partir da descrição dos participantes do fenômeno estudado; após, articular o insight psicológico em cada uma das unidades significativas; e, por fim, sintetizar todas as unidades de significado transformadas em uma afirmação consistente, relacionada com as experiências dos participantes (estrutura da experiência). ${ }^{14,16}$

O projeto foi aprovado pelo Comitê de Ética em Pesquisa sob o protocolo $n^{\circ}$ CEP/HUJM $605 / 09$.

\section{RESULTADOS E DISCUSSÃO}

Das quatorze entrevistas realizadas, nove foram com clientes que passaram pela experiência do exame físico na clínica cirúrgica e cinco na clínica médica. Tal fato se deve a maior rotatividade de clientes que ocorre na clínica cirúrgica em relação aos da clínica médica. Dentre os participantes, dez eram do sexo feminino e quatro do sexo masculino, a idade dos sujeitos variou de 19 a 64 anos e o período de internação de três a quatorze dias.

\section{O exame físico localiza a doença no corpo, tornando visível o invisível.*}

A experiência de ser submetido ao exame físico se revelou como procedimento capaz de localizar a doença no corpo, visto que a experiência é vivida pelo sujeito a partir de um certo ponto de vista, não como espectador, mas como parte dele. ${ }^{2}$

Para os clientes, o exame físico realizado pelos profissionais de saúde/enfermagem possibilita identificar e localizar a doença no corpo por meio das alterações biológicas que estão ocorrendo e que podem vir a ocorrer no seu corpo. Além disso, é considerado pelo cliente como algo importante e que deve ser realizado, pois possibilita ao profissional de saúde/enfermagem acompanhar o tratamento e a evolução da doença.

As falas abaixo revelam este achado:

[...] o exame do nódulo, antes da cirurgia que apertavam bastante, aqui na parte do pescoço... eu fico imaginando assim, se eles [profissionais de saúde/ enfermagem] fazem aquele exame do pescoço, é para ver se tinha algum caroço, algum nódulo, eles procuravam encontrar alguma coisa de anormal (E2).

[...] eu acho [o exame físico] que é para se tiver algum problema como de taquicardia, que é a alteração do coração, acredito que já estão sabendo se vai atacar ou não (E1).

[...] eu achava [o exame físico] que era para eles [profissionais de saúde/enfermagem] saberem o que estava acontecendo comigo, como o problema do meu coração (E9).

\footnotetext{
* Este tópico se refere à primeira unidade de significado (categoria) construída na dissertação de mestrado em enfermagem, intitulada: "A experiência do exame físico para o cliente: um olhar fenomenológico". 
[...] o exame físico é para ver como eu estava me sentindo, se tivesse algo errado já tratava (E13).

Pelas falas fica evidente que os clientes possuem uma percepção em relação ao exame físico, atribuindo-lhe um significado. Este significado pode estar relacionado com experiências anteriores no decorrer das etapas da vida.

As experiências relacionadas às etapas da vida são aquelas vivenciadas na infância, adolescência e fase adulta, ou seja, o cliente em algum momento de sua vida passou pela experiência de submeter seu corpo ao exame físico. Na relação entre mãe e filho, o ato de examinar o corpo é comum, a exemplo de quando o filho se queixa de dor e é imediatamente submetido a um olhar/inspeção da mãe pelo toque, palpação local na tentativa de encontrar a causa da dor. Desse modo, cada vez que se tem uma experiência similar, a experiência anterior é retomada, porém, não da mesma forma, mas encaixada às novas, se transformando em experiências vivas, ressignificadas.

Merleau-Ponty elucida esse fenômeno ao afirmar que o mundo vivido está aquém do mundo objetivo e é nele que podemos compreender tanto o direito como os limites do mundo objetivo, ao restituir aos organismos a sua maneira própria de tratar o mundo. Para o referido autor, é como reencontrar os fenômenos, a camada de experiência viva, ou seja, o outro e as coisas que nos são dadas no estado nascente para despertar a percepção.

Assim, com as experiências anteriores da vida, é possível aos clientes retornar ao estado nascente e se reencontrar, dando-lhe um significado. A retomada das experiências passadas nas experiências presentes se processa no mundo vivido pela engrenagem de umas nas outras. ${ }^{3}$

O mundo é o que vemos, contudo precisamos aprender a vê-lo e para isso é mister nos igualarmos pelo saber. ${ }^{17}$ Dessa maneira, a experiência do exame físico para o cliente não é a somatória de eventos anteriores e, sim, uma engrenagem que a cada momento foi adquirindo um novo saber, assumindo novo significado, possibilitando-lhe reencontrar e ampliar o seu modo de perceber o mundo, visto que "a percepção presente consiste em reaprender, apoiando-se na posição atual, a série das posições anteriores que se envolvem umas as outras". 3:194

As experiências da vida ocorrem por meio do corpo. É com este e por meio deste, que se vivencia a experiência, assim, o corpo tem uma relação direta com o mundo, é o ponto de vista/ referência sobre o mundo, é um dos objetos desse mundo que está dado. É o meio natural, onde o sujeito se conhece, campo de todos os pensamentos e percepções, por isso, antes de qualquer análise que se possa fazer dele, deve-se consagrar o sujeito ao mundo. ${ }^{3}$ Apreendemos assim, que a experiência do exame físico pelo cliente se dá na relação de seu corpo com o mundo, junto às engrenagens das experiências anteriores.

Para os clientes a experiência do exame físico também foi percebida como algo importante, por possibilitar identificar as alterações no corpo. As seguintes falas revelam essa maneira de pensar:

[...] eu achava importante o exame físico, era para ver tudo assim o que tem em você [...] Começou a me olhar, verificar, apertar e mostrar [...] acho que é para ver a hérnia (E3).

[...] ah! eles [profissionais de saúde/enfermagem] estavam me examinando para saber como eu estava... assim para saber se estava sentindo alguma coisa, achei que deveria mesmo me olhar (E11).

Os clientes chegam a demonstrar em suas falas que a execução do exame físico se torna importante, que é considerado um cuidado relevante dispensado pela equipe de saúde/enfermagem. $\mathrm{O}$ corpo necessita ser examinado para que se possa avaliar suas condições anátomo-fisiológicas, identificar as condições de saúde (saudável/doente), uma vez que é por meio deste que se visa o mundo, se faz presente nas experiências da vida, pois "o nosso corpo é para nós o espelho de nosso ser" 3:236

Quando os clientes referem que a realização do exame físico visa saber o que estão sentindo e este sentir diz respeito ao funcionando do corpo, internamente e externamente. Quer dizer, se apresenta alguma alteração, por exemplo, uma queixa de dor, presença de um nódulo, o aparecimento do dado clínico indicará que algo interno não está bem e necessita ser reajustado, ser tratado. Esta condição possibilitará tornar visível o que estava invisível, oculto no corpo.

Assim, "toda a experiência do visível sempre é dada no contexto dos movimentos do olhar, o espetáculo visível pertence ao tocar nem mais nem menos do que as qualidades táteis", ${ }^{17: 133} \mathrm{o}$ todo visível é moldado no sensível, todo o ser tátil está voltado de alguma maneira à visibilidade. Há, portanto, imbricação entre o que é tocado e quem toca, entre o tangível e o visível que está nele incrustado.

Já o invisível, é aquilo que se revela por trás dos olhos, dos gestos, vindo de não sei que fundo falso do espaço, ou seja, do mundo privado. E por 
um momento é nele que se vive, sendo apenas aquele que responde a interpelação que é feita. Nesse momento, o meu mundo privado deixou de ser apenas meu, é agora instrumento manejado pelo outro, dimensão de uma vida generalizada que se enxertou na minha. ${ }^{17}$

A fala abaixo revela que o exame físico executado no corpo visível faz transparecer através do tecido, da carne o mundo privado, o que está atrás dos olhos, o que está invisível:

[...] o exame é bom para gente né, está vendo tudo, vendo você internamente, vendo como se está... eles perguntavam [os profissionais de saúde/enfermagem], pesquisavam e iam medir o pulso, escutavam o pulmão, iam estudar o corpo, o tornozelo pegando mesmo, pegava com a mão, esticava o braço e sentia a pulsação e também com aquele aparelho (E6).

No entanto, nos é revelado ser por meio da experiência do sujeito, que se tem acesso ao visível total, reunindo os dois lados do corpo, o corpo objetivo e o fenomenal. ${ }^{17} \mathrm{Ou}$ seja, é por meio da experiência que o corpo revela o invisível para nós, unindo as propriedades do corpo, o objeto e o sujeito, no corpo sensível.

O corpo é único em duas fases, incorpora todo o sensível visto que, graças ao mesmo movimento, incorpora-se a si mesmo num sensível em si. Dessa forma, "temos ou não temos um corpo, isto é, não um objeto de pensamento permanente, mas uma carne que sofre quando ferida, e mãos que apalpam?". 17:133

Neste pensar, sujeito como corpo único arraigado à experiência do sensível em si, leva-nos a entender este ser-no-mundo, como um sujeito que realiza a junção do psíquico e do fisiológico. Desta união surge a vontade de ter um corpo são ou a recusa do corpo doente que no engajamento de um certo mundo físico e inter-humano continua a se estender para o seu mundo.

A fala abaixo revela a ligação do mundo fisiológico ao psíquico:

[...] você quer que as pessoas [profissionais de saúde/enfermagem] venham olhar você, para tratar, ver se você está bem antes da cirurgia, para ver se você pode fazer a cirurgia, medem a sua pressão, ver seu corpo como que está reagindo ali na hora e mesmo depois da cirurgia, você não vê a hora de chegar alguém ali para te dar um conforto, é gratificante (E10).

O que permite tornar a ligar o fisiológico e o psíquico é o fato de que, reintegrados à existência, são orientados para um pólo intencional ou para um mundo. O homem não é um psiquismo unido ao organismo, mas este vaivém da existência que ora se deixa ser corporal e ora se dirige aos atos pessoais. ${ }^{3}$ Assim, o exame físico realizado por profissionais de saúde/ enfermagem é percebido pelo cliente não apenas como forma de identificar e tratar as questões orgânicas, mas também para promover conforto (necessidade de ter alguém próximo para escutar, tocar e que se preocupa com seu estado de saúde de maneira geral).

Desvelar a experiência do cliente que foi submetido ao exame físico é percebê-lo como capaz de apreender as mudanças que ocorrem no seu corpo, como podemos observar na seguinte fala:

[...] eu acho que aquele exame que estavam fazendo em mim ali é, porque é pós-operatório e eles [acadêmicos de enfermagem/medicina] também estão estudando precisam saber como que a gente está depois da cirurgia para tratar, porque não é todo mundo que fica bem, alguns ficam com dores (E10).

Diante desta fala do cliente, a experiência de ser submetido ao exame físico no pós-operatório tem por objetivo o acompanhamento do estado geral de sua saúde.

O corpo do cliente examinado antes de um procedimento cirúrgico é aquele que se tinha antes da internação, seu corpo habitual. O trauma cirúrgico traz mudanças no corpo habitual que se transforma em corpo atual, adquirindo novo aspecto/forma devido a presença da incisão cirúrgica, curativo, limitação de atividades.

Entretanto, no mesmo momento em que o mundo costumeiro suscita no cliente intenções habituais e, por certa situação não se pode mais realizá-las, o corpo se comporta como duas camadas distintas, a do corpo habitual e a do corpo atual. Na evidência deste mundo completo em que ainda figuram partes do corpo manejáveis, o doente encontra a certeza de sua integridade (corpo habitual), mas, no momento em que o mundo mascara sua deficiência, ele não pode deixar de revelá-la (limitação de movimentos, dor, desconforto), corpo atual.

O exame físico também é percebido pelos clientes como procedimento que dá aos profissionais de saúde/acadêmicos, aos que estudam o corpo humano a possibilidade de identificar, diagnosticar e tratar o corpo. Esta concepção pode estar relacionada ao processo de formação profissional ao utilizar as técnicas de inspeção, palpação, percussão e ausculta.

É porque ele [profissional de saúde/enfermagem] vê como que está internamente [órgãos/siste- 
mas] e tem que sentir, pegar, escutar os batimentos, para ver se a gente está com alguma coisa (E6).

Esta fala evidencia a relevância que as técnicas do exame físico apresentam para o cliente. A técnica da inspeção, por meio do sentido da visão, revela ser significativa, pois busca as alterações visíveis ao olhar. Seguindo essa linha de pensamento, construímos pela ótica o fragmento do mundo cuja imagem pode formar-se a cada momento em nossa retina. O campo visual é o meio singular e o visível é o que se apreende com os olhos. ${ }^{3}$

Assim sendo, inspecionar o cliente no momento do exame físico é apreender os fragmentos, as alterações biológicas com os olhos. É preciso que a percepção guarde, no fundo de si, todas as relevâncias corporais delas; é olhando, é ainda com meus olhos que chego à coisa verdadeira. ${ }^{17}$

A palpação possibilita que os profissionais utilizando as mãos delimitem áreas, estruturas, sintam a textura. Permite dar os contornos, definindo o local da lesão, tamanho, profundidade, características. Sentir o outro por meio do toque também é uma forma de aproximação, é a comunicação vital com o mundo que o torna presente para nós. ${ }^{3}$

A experiência tátil, por estar aderida à superfície do corpo não se desdobra diante de nós, inteiramente como objeto. Enquanto sujeito do tato, não se pode estar em todas as partes do corpo, pois é pelo corpo que se vai ao mundo, a experiência tátil não se centra em mim. Não sou eu que toco, é meu corpo, só posso tocar eficazmente se o fenômeno encontra repercussão em minha consciência; a unidade e a identidade do fenômeno tátil não se realizam por uma síntese de recognição no conceito, elas estão fundadas na unidade e na identidade do corpo enquanto conjunto sinérgico. ${ }^{3}$

Assim, ao retomar o contato com o corpo e com o mundo, é a nós mesmos que iremos reencontrar, como um eu natural e o sujeito da percepção.

\section{CONSIDERAÇÕES FINAIS}

Apreendemos que a abordagem fenomenológica constitui uma alternativa de pesquisa para a enfermagem, uma vez que descreve a experiência vivida do ser humano e, fundamentada no ato perceptivo surge a possibilidade do olhar para o outro, situado no entrelaçamento do corpo com o mundo em sua totalidade de vida.

$\mathrm{Na}$ área da saúde/enfermagem estamos em contato direto com o corpo do cliente por meio da realização do exame físico, para que se possa prestar e direcionar o cuidado. Para os clientes, a experiência do exame físico se revelou importante e o uso de técnicas próprias permite localizar a doença no corpo, tornando visível o invisível, por conseguinte, a possibilidade de tratar e acompanhar a evolução de seu estado geral de saúde.

O exame físico executado no corpo visível faz transparecer através do tecido, da carne, o mundo privado, o que está atrás dos olhos, o que está invisível. É por meio do corpo que nos fazemos presentes, que visamos o mundo, que temos as experiências da vida, por isso o corpo necessita ser examinado para que se possa detectar a alteração biológica e fazer aparecer o que está oculto.

O corpo é único em duas fases, une as propriedades do corpo, o objeto e o sujeito, no corpo sensível, ou seja, é na junção do corpo fisiológico/ psíquico que se tem a percepção do mundo e o significado para as experiências da vida.

O olhar para o cliente que se submete ao exame físico, agora se mostra sob novas perspectivas, com isso somos desafiados a rever nossas práticas, mudar a forma de se aproximar, falar, tocar, ver o corpo como ser-no-mundo.

A utilização do referencial de Merleau-Ponty mostrou-se pertinente, pois permitiu desvelar a experiência do exame físico para o cliente e sua relação com o corpo e o mundo.

Entretanto, vale ressaltar que este estudo não tem a pretensão de esgotar o assunto, uma vez que a síntese é pessoal e dinâmica, podendo ter uma multiplicidade de perspectiva a depender do investigador. Assim sendo, o real se mostra por perfis e as verdades em pesquisa nunca se esgotam, estão sempre sendo interrogadas visto que não são verdades absolutas.

\section{REFERÊNCIAS}

1. Potter PA, Perry AG. Fundamentos de enfermagem. $5^{\mathrm{a}}$ ed. Rio de Janeiro (RJ): Guanabara Koogan; 2004.

2. Abdelmaler AA, Gérard JL. Ciências humanas e cuidados de saúde: manual para profissionais de saúde. Lisboa (PT): Instituto Piaget; 1995.

3. Merleau-Ponty M. Fenomenologia da percepção. $3^{\mathrm{a}}$ ed. São Paulo (SP): Martins Fontes; 2006.

4. Paula JC, Cintra FFA. A relevância do exame físico do idoso para a assistência de enfermagem hospitalar. Acta Paulista Enferm. 2005 Jul-Set; 18(3):301-6.

5. Luizari MRF, Ohara CVS, Horta ALM. Avaliando a aprendizagem do exame físico de enfermagem 
no contexto da semiologia pediátrica. Acta Paulista Enferm. 2008 Jan-Mar; 21(1):66-71.

6. Fernandes MGO, Barbosa VL, Naganuma, M. Exame físico de enfermagem do Recém Nascido a termo: Software auto-instrucional. Rev Latino-am Enfermagem. 2006 Mar-Abr: 14 (2):243-50.

7. Nakatani AYK, Carvalho EC, Bachion MM. O ensino do exame físico pulmonar através do método da problematização. Rev Latino-am Enfermagem. 2000 Nov-Dez; 14 (6):117-23.

8. Sousa VD, Barros ALBL. O ensino do exame físico em escolas de graduação em enfermagem do município de São Paulo. Rev Latino-am Enfermagem. 1998 Jul; 6(3):11-22.

9. Soares VV, Vieira LJES. Percepção de crianças hospitalizadas sobre realização de exames. Rev Esc Enferm USP. 2004 Set;38(3):298-306.

10. Greenwood AS, Machado MFSA, Sampaio NMV. Motivos que levam mulheres a não retornarem para receber o resultado de exame Papanicolau. Rev Latino-am Enfermagem. 2006 Jul-Ago; 14(4):503-9.

11. Ramos AS, Palha PF, Júnior MLC, Sant'Anna SC, Lenza NFB. Perfil de mulheres de 40 a 49 anos cadas- tradas em um núcleo de saúde da família, quanto à realização do exame preventivo de Papanicolau. Rev Latino-am Enfermagem. 2006 Mar-Abr; 14(2):170-4.

12. Paula AF, Madeira AMF. O exame colpocitológico sob a ótica da mulher que vivencia. Rev Esc Enferm USP. 2003 Set; 37(3):88-96.

13. Merighi MAB, Hamano L, Cavalcante LG. O exame preventivo do câncer cérvico - uterino: conhecimentos e significado para as funcionárias de uma escola de enfermagem de uma instituição pública. Rev Esc Enferm USP. 2002 Set; 36 (3):289-96.

14. Terra MG, Silva LC, Camponogara S, Santos EKA, Sousa AIJ, Erdmann AL. Na trilha da fenomenologia: um caminho para a pesquisa em enfermagem. Texto Contexto Enferm. 2006 Oct-Dec; 15(4):672-8.

15. Polit DF, Beck CT, Hungler BP. Fundamentos de Pesquisa em enfermagem. $5^{\text {a }}$ ed. Porto Alegre (RS): Artmed; 2004.

16. Martins J, Bicudo MAV. A pesquisa qualitativa em psicologia: fundamentos e recursos básicos. São Paulo (SP): Moraes; 2005.

17. Merleau-Ponty M. O visível e o invisível. $4^{\mathrm{a}}$ ed. São Paulo (SP): Perspectiva; 2007. 